\title{
sciendo
}

\author{
BULGARIAN ACADEMY OF SCIENCES
}

CYBERNETICS AND INFORMATION TECHNOLOGIES • Volume 19, No 3

Sofia $2019 \quad$ Print ISSN: 1311-9702; Online ISSN: 1314-4081

DOI: $10.2478 /$ cait-2019-0025

\section{Group Decision Making in Evaluation and Ranking of Students by Extended Simple Multi-Attribute Rating Technique}

\author{
Daniela Borissova ${ }^{1,2}$, Delyan Keremedchiev ${ }^{1,3}$ \\ ${ }^{1}$ Institute of Information and Communication Technologies, Bulgarian Academy of Sciences, 1113 Sofia, \\ Bulgaria \\ ${ }^{2}$ University of Library Studies and Information Technologies, 1784 Sofia, Bulgaria \\ ${ }^{3}$ New Bulgarian University, 1618 Sofia, Bulgaria \\ E-mails:dborissova@iit.bas.bg delyan.keremedchiev@gmail.com
}

\begin{abstract}
The paper deals with evaluation and ranking of students taking into account two main criteria of the learning - theoretical knowledge and practical skills. These criteria are divided into several sub-criteria to reflect different aspects of the learning outcomes. To make such complex evaluation the proper utility function based on simple multi-attribute rating technique is proposed. This new utility function includes not only the evaluation score and weighted coefficients for criteria importance, but considers also additional coefficients that indicate how theoretical knowledge and practical skills will take part in the aggregated final assessment. The formulated model is applied for the assessing of the students on web programming. The students are ranked under three different cases where the theoretical knowledge and practical skills take different part in the aggregated assessment. The obtained results demonstrate the applicability of the described approach by providing different ranking depending on the importance of the theoretical and practical aspects.
\end{abstract}

Keywords: Students' assessments, ranking, web programming, group decision making.

\section{Introduction}

An important role in the modern web programming plays the recent development of HTML5 standard where significant technological capabilities are added to the World Wide Web [1]. The capability of HTML5 could be used not only for web sites development but also it contributes for different web applications [2].

The dynamics in contemporary Information and Communication Technologies (ICT) imposes the use of different approaches in developing of e-Learning tools. In [3] two quantitative methods are proposed based on the one-factor regression analysis and modified parametrical modelling. In the contexts of e-Learning the integration of ICT and database contributes to develop user friendly environment to support the 
learning process [4]. Along with these, a proper testing system is needed during the learning and teaching process. The acquired knowledge of different subjects could be realized by using Web-based e-Testing system [5]. In addition, the peer and selfassessment in Moodle e-Learning environment could be done by implementation of gamification in assessment activities as it is demonstrated in [6]. It is highly important to propose to the students a friendly environment for description and visualisation of the learning material that helps for better understanding and improving the skills in computer programming $[4,7]$.

During the last two decades web applications have become more popular due to the new web standards (like HTML5, CSS3, DOM, JavaScript, Node.js, etc.) and a variety of web programming languages. All of these web-programming languages are subject to different courses in the bachelor programs and are considered as mandatory for the students in Computer Science. Depending on the key accent related to theoretical or practical skills, the students' competence should be properly assessed. The theoretical knowledge is acquired during the lectures while the practical skills are acquired and demonstrated during the exercises. The rank list could serve as a basis when students are to be profiled for future specialization. Depending on the particular specialization, it could be more theoretically or more practically oriented. Thus proper students' assessments are needed.

The assessment of students and their subsequent ranking could be viewed as Multi-Attribute Decision Making (MADM) problem, where the students can be considered as alternatives while the theoretical knowledge and practical skills could be transformed into evaluation criteria.

The aim of the paper is to propose a flexible group decision making model for students' assessment that could be adjusted to different purposes of ranking. For this purpose, an extended model based on classical rating technique by score is formulated. It includes coefficients of importance set by the lecturers in theories and practice that reflect the importance of their opinions when aggregating the final group decision. The proposed model is able to get different rank lists of students depending on the demonstrated theoretical knowledge and practical skills and their contributions in the final assessment.

The rest of the paper is organized as follows: Section 2 contains the literature review; Section 3 describes the proposed extended model based on Simple MultiAttribute Rating Technique (SMART) for determination generalized assessment; Section 4 comprises a case study for assessments of students from Web Programming course; Section 5 discusses the results, and Section 6 provides a conclusion and future work directions.

\section{Literature review}

Different techniques have been proposed to cope with multi-criteria decision-making and a detailed review of the literature with their applications is given [8]. In decision making, two different strategies can be used to identify the best choice among a given set of alternatives - compensatory and non-compensatory [9]. Compensatory decision making strategies are based on using tility function that should be 
maximized [10]. In contrast to compensatory strategies, non-compensatory strategies apply heuristics for faster evaluation of alternatives with minimal effort and acceptable loss of accuracy [9]. In multi-criteria decision making, the Decision Maker's (DM) preferences modelling play an essential role [11]. Depending on the investigated problems, the evaluation criteria can be expressed by quantitative, qualitative, fuzzy or mixed model. In such situations, the multi-criteria decision models with fuzzy relations could be best suited [12]. The authors show that except the evaluation criteria, the criteria weights can be expressed also by fuzzy numbers or fuzzy relations to articulate the importance between criteria [13]. The modelling of preferences deals with the problems concerning the expression of DM's preferences. A brief review of the problems of DM's preferences expression is decision models given in [14]. When the problem has to be approached by group decision-making, the main efforts should be focused on the way of DMs' preferences aggregation. It should be noted that availability of some kind of uncertainty requires using proper multi-criteria group decision making models [15].

The students' assessment and subsequent ranking are common activities for each university. There are different approaches to make different classification depending on its purpose. For example, data mining methods are used for classification by predicting student performance [16]. Using the idea of the described multi-criteria models for cluster design could contribute to the evaluation, ranking and distribution of the students in groups [17]. For the purpose of the students' assessment and subsequent ranking the MADM based on utility function seems to be the more suitable approach. The well known MADM problems could be approached by methods based on some utility function [18]:

$$
A^{*}=\left\{u_{i}(x) \mid \max u_{i}(x)\right\}, i=1,2, \ldots, M,
$$

where the numbers of alternatives are expressed by index $i, i=1,2, \ldots, M ; u_{i}$ denotes the utility function of $i$-th alternative and the best alternative $A^{*}$ achieves the maximum value of the used utility function.

The most representative example of the methods based on utility function is the Simple Additive Weighting (SAW) [19]. The utility function of SAW sums up the multiplication of the scores toward evaluation criteria for the alternatives with the weights for importance of the criteria. Another model with utility function is the weighted product model, which is similar to SAW. The main difference between WPM and SAW is in the mathematical operations and instead of summing it uses multiplication of scores in respect to the evaluation criteria raised to a power of the relative weight for the corresponding criterion [19]. SMART relies on linear additive utility function [20]. The VIKOR and TOPSIS methods are also utility-based and their function represents the closeness to the ideal [21]. Beside these widely used MADM methods their variations and combinations are proposed to cope with different problems $[22,23]$. The determination of the best alternative could be obtained by using of combinatorial optimization where binary integer variables contribute for selection of the best alternative taking into account additional coefficients about the importance of experts' opinions in determination of the final group decision [24]. 


\section{Extended model based on SMART for determination generalized assessment considering acquired theoretical knowledge and practical skills}

The determination of more objective generalized assessment of students requires considering different aspects of the acquired theoretical knowledge and practical skills. For this purpose these two main criteria of evaluation could be expressed by using some sub-criteria for more detailed evaluation in forming the overall generalized evaluation as shown in Table 1 .

Table 1. Input data for aggregated assessment of the students

\begin{tabular}{|c|c|c|c|c|}
\hline \multirow[b]{2}{*}{ Main criteria } & \multirow[b]{2}{*}{ Sub-criteria } & \multicolumn{2}{|c|}{ Criteria weights } & \multirow{2}{*}{$\begin{array}{l}\text { Weights for theoretical } \\
\text { and practical outcomes } \\
\text { (DMs) }\end{array}$} \\
\hline & & $\begin{array}{c}\text { DM-1 } \\
\text { (lecturer) }\end{array}$ & $\begin{array}{c}\mathrm{DM}-2 \\
\text { (instructor) }\end{array}$ & \\
\hline \multirow{4}{*}{$\begin{array}{c}C_{1}-\text { Theoretical } \\
\text { knowledge (Lectures) }\end{array}$} & $C_{11}$ & $\left(w_{11}\right)$ & --- & \multirow{4}{*}{$\alpha$} \\
\hline & $C_{12}$ & $\left(w_{12}\right)$ & --- & \\
\hline & $\ldots$ & $\ldots .$. & --- & \\
\hline & $C_{1 N}$ & $\left(w_{1 N}\right)$ & --- & \\
\hline \multirow{4}{*}{$\begin{array}{c}C_{2}-\text { Practical skills } \\
\text { (Exercises) }\end{array}$} & $C_{21}$ & --- & $\left(w_{21}\right)$ & \multirow{4}{*}{$\beta$} \\
\hline & $C_{22}$ & --- & $\left(w_{22}\right)$ & \\
\hline & $\ldots$ & --- & $\ldots$ & \\
\hline & $C_{2 M}$ & --- & $\left(w_{2 M}\right)$ & \\
\hline
\end{tabular}

The main criterion concerning the theoretical knowledge $C_{1}$ is composed of $N$ number sub-criteria $\left(C_{1}=\left\{C_{11}, C_{12}, \ldots, C_{1 N}\right\}\right)$, while the second criterion representing the practical skills $C_{2}$ is composed of $M$ number sub-criteria $\left(C_{2}=\left\{C_{21}, C_{22}, \ldots, C_{2 M}\right\}\right)$. The lecturer (DM-1) responsible for theoretical knowledge evaluation should determine corresponding weighted coefficients that express relative importance between sub-criteria $\left(C_{11}, C_{12}, \ldots, C_{1 N}\right)$. The evaluation of the theoretical knowledge could be done by using different tests $[25,26]$. The instructor (DM-2) should determine other weighted coefficients for relative importance between sub-criteria $\left(C_{21}, C_{22}, \ldots, C_{2 M}\right)$ for the practical skills. In such way, both DMs independently could express the evaluations and corresponding weight toward the criteria importance. For a more realistic assessment, it is suggested to use additional weighted coefficients about the theoretical $(\alpha)$ and practical $(\beta)$ results (Table 1$)$.

To get a generalized assessment about the students' performance taking into account the acquired theoretical knowledge and practical skills, an extended model based on SMART is proposed. The utility function for the extended SMART model (e-SMART) is as follows:

$$
\max \left(\alpha \sum_{j=1}^{N} w_{j} e_{i j}+\beta \sum_{k=1}^{M} w_{k} e_{i k}\right), i=1,2, \ldots, S,
$$




$$
\begin{aligned}
& \sum_{j=1}^{N} w_{j}=1, \\
& \sum_{k=1}^{M} w_{k}=1, \\
& \alpha+\beta=1,
\end{aligned}
$$

where $w_{j}$ is the coefficient for relative importance between evaluation sub-criteria with regard to the theoretical knowledge, $w_{k}$ is the coefficient for relative importance about the sub-criteria in regard to the practical skills, $e_{i j}$ represents evaluation score about $i$-th student toward $j$-th criterion in respect of the theory, $e_{i k}$ is the evaluation score about $i$-th student toward $k$-th criterion in respect of the practice.

The modification of e-SMART consists in using additional weighed coefficients $\alpha$ and $\beta$ that indicate how theoretical knowledge and practical skills take part in the aggregated final assessment. There is one additional restriction about these coefficients as expressed by relation (5). The normalization is needed to provide the comparable dimensions between the coefficients for relative importance of subcriteria $\left(w_{j}\right.$ and $\left.w_{k}\right)$, additional weighed coefficients $(\alpha$ and $\beta$ ) and sub-criteria evaluations $e_{i j}$ and $e_{i k}$.

The fact that the degree of knowledge and practical skills vary should be taken into account when aggregating the final students' assessment. Therefore, it is appropriate to distinguish the importance of theoretical and practical outcomes using the proposed weighted coefficients for the purpose of evaluation and ranking.

\section{Numerical Application of the e-SMART for Students' Assessment on Web Programming Course}

The knowledge in Web programming can be divided as theoretical knowledge and practical skills. The first part of assessment is the theoretical knowledge of students? that is realized via test format by the lecturer. The second part of assessment is a result of demonstrated practical skills during the exercises. The students finish the course of web programming with two tests and a project on a chosen topic for website development. The content of these tests covers the theoretical knowledge of a complete course of web programming including the latest technologies in HTML, CSS and JavaScript. The acquired knowledge is tested periodically during the exercises. At the end of the course, the developed website project should be functional, but it is not obligatory to be fully built. In addition, the students should demonstrate their creativity and the developed website should reflect the acquired knowledge in the studied technologies of HTML5, CSS3 and JavaScript.

The overall estimation of the students' practical skills is done by using several criteria. These criteria are related to different aspects of developed website and include: 1) visual design, 2) user interface, 3) content strategy, 4) technical implementation, and 5) creativity, as it is shown in Fig. 1. 


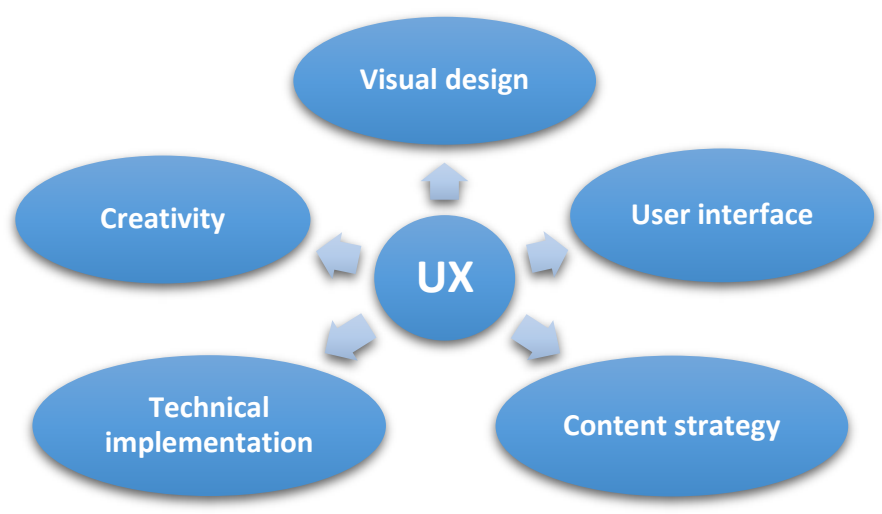

Fig. 1. Some basic aspects of User Experience (UX) design

User experience (UX) design expresses the user satisfaction with a product by considering the usability, accessibility, and satisfaction provided by the website usage. It involves the integration of the particular product, including some aspects of branding, design, usability and functionality. In the context of the current paper, the practical skills of students are assessed toward five main features as visual design, user interface, content strategy, technical implementation and creativity considered as a part of UX. UX design could be interpreted as a part of art and science that contributes for users' satisfaction of usage of the product.

Visual design is related to the aesthetical view of any user interface. In the era of digital technologies, the user interface is an essential component for the success of any product. The visual design focuses on the used elements including colours, images, fonts and symbols to convey the right message to the users concerning particular content.

The user interface is a part of visual design but it has its own specifics that could be realized by horizontal or vertical menus or combining both of them. All of these navigations should be carefully thought out in respect with the topic of the presented project. The web programming languages, such as HTML and CSS allow making it easier to create such user interface that best fits the content of the website. Due to this, the user interface is used by a separate evaluation criterion. The well designed interface should make the user more effective when using the presented navigations.

Content strategy is focused on the planning, creation and managing of website content. The content of pages includes not only the plain text pages but involves also appropriate images and multimedia.

Technical implementation involves particular aspects of the used technology to implement the overall design including the responsive design. The usage of CSS media queries makes possible to adapt the website to different screen resolutions including mobile devices that is the basic role of responsive design.

The main aspect of Creativity is the uniqueness of overall design. It includes the combination of colour schemes that could make essential difference of design. Another important feature of the creativity is the typography. It consists of choosing the most suitable fonts in relation to the specific topic of the project. 
All of the described criteria for acquired theoretical knowledge together with practical skills are used as evaluation criteria of the proposed new utility function. The trainers in lectures and exercises are considered as a group composed of two decision makers.

The proposed e-SMART model has been applied during the forming the assessments of the students of a web programming course. The evaluation process is based on two main criteria and several sub-criteria as shown in Table 1. Each year the students that pass the course of web programming are more than 200. For example, the number of students for academic year 2018/2019 in bachelor programme "Information and Computer Sciences" at the University of Library Studies and Information Technologies is 212. It should be mentioned that the students' number that pass web programming course at New Bulgarian University is more than 120 . To provide quality of education the students are usually divided into several groups.

The input data for numerical application of the proposed e-SMART model are based only on one group composed of 21 students. The evaluation score for theoretical knowledge is composed of two tests, while practical skills are determined based on the developed project for website concerning five criteria about visual design; user interface; content strategy; technical implementation and creativity. The obtained data about the theoretical and practical students' performance are shown in Table 2.

Table 2. Evaluation score for a group of students

\begin{tabular}{|c|c|c|c|c|c|c|c|c|c|c|c|c|c|c|c|c|c|c|c|c|c|}
\hline \multirow{2}{*}{$\begin{array}{l}\text { Sub- } \\
\text { cri- } \\
\text { teria }\end{array}$} & \multicolumn{21}{|c|}{ Students and corresponding evaluation score } \\
\hline & $S_{1}$ & $S_{2}$ & $S_{3}$ & $S_{4}$ & $S_{5}$ & $S_{6}$ & $S_{7}$ & $S_{8}$ & $S_{9}$ & $S_{10}$ & $S_{11}$ & $S_{12}$ & $S_{13}$ & $S_{14}$ & $S_{15}$ & $S_{16}$ & $S_{17}$ & $S_{18}$ & $S_{19}$ & $S_{20}$ & $S_{21}$ \\
\hline$C_{11}$ & 0.97 & 0.70 & 0.81 & 1.00 & 0.70 & 0.85 & 0.77 & 0.78 & 0.95 & 0.98 & 0.75 & 0.70 & 0.84 & 1.00 & 0.65 & 0.93 & 0.90 & 1.00 & 0.72 & 0.95 & 0.68 \\
\hline$C_{12}$ & 0.70 & 0.65 & 0.90 & 0.75 & 0.65 & 0.90 & 0.85 & 0.82 & 0.85 & 0.75 & 0.70 & 0.64 & 0.95 & 0.80 & 0.82 & 0.85 & 0.87 & 0.78 & 0.65 & 0.70 & 0.70 \\
\hline$C_{21}$ & 0.80 & 0.88 & 0.90 & 0.65 & 0.85 & 0.80 & 0.65 & 0.70 & 0.80 & 0.70 & 0.67 & 0.60 & 0.75 & 0.80 & 0.70 & 0.82 & 0.80 & 0.80 & 0.70 & 0.60 & 0.60 \\
\hline$C_{22}$ & 0.77 & 0.75 & 0.88 & 0.70 & 0.75 & 0.80 & 0.70 & 0.60 & 0.85 & 0.75 & 0.72 & 0.65 & 0.75 & 0.70 & 0.68 & 0.95 & 0.85 & 0.85 & 0.85 & 0.77 & 0.80 \\
\hline$C_{23}$ & 0.86 & 0.70 & 0.80 & 0.68 & 0.72 & 0.75 & 0.70 & 0.75 & 0.75 & 0.75 & 0.66 & 0.70 & 0.80 & 0.75 & 0.75 & 0.66 & 0.70 & 0.78 & 0.78 & 0.83 & 0.80 \\
\hline$C_{24}$ & 0.68 & 0.65 & 0.84 & 0.75 & 0.68 & 0.90 & 0.77 & 0.75 & 0.80 & 0.90 & 0.80 & 0.78 & 0.85 & 0.89 & 0.68 & 0.81 & 0.73 & 0.63 & 0.82 & 0.90 & 0.82 \\
\hline$C_{25}$ & 0.90 & 0.73 & 0.80 & 0.90 & 0.74 & 0.85 & 0.62 & 0.65 & 0.85 & 0.80 & 0.78 & 0.75 & 0.90 & 0.75 & 0.70 & 0.90 & 0.75 & 0.70 & 0.73 & 0.76 & 0.77 \\
\hline
\end{tabular}

The two tests are with different degree of complexity and this is taken into account by assigning of corresponding weights for these two criteria. These weights are provided by the DM-1 while the weights for the practical skills evaluation are given from DM-2. The particular values for criteria importance are shown in the first part of Table 3 together with the weights for DMs when generalized assessment is formed. 
Table 3. Weights for criteria importance and weights for students' learning outcomes

\begin{tabular}{|c|c|c|c|c|c|c|c|c|}
\hline \multirow{4}{*}{$\begin{array}{c}\text { Sub- } \\
\text { criteria }\end{array}$} & \multirow{3}{*}{\multicolumn{2}{|c|}{$\begin{array}{l}\text { Weights for sub- } \\
\text { criteria importance }\end{array}$}} & \multirow{3}{*}{\multicolumn{2}{|c|}{$\begin{array}{c}\text { Case-1 } \\
\text { Weights for } \\
\text { outcomes (DMs) }\end{array}$}} & \multirow{3}{*}{\multicolumn{2}{|c|}{$\begin{array}{c}\text { Case-2 } \\
\text { Weights for } \\
\text { outcomes (DMs) }\end{array}$}} & \multirow{3}{*}{\multicolumn{2}{|c|}{$\begin{array}{c}\text { Case-3 } \\
\text { Weights for } \\
\text { outcomes (DMs) }\end{array}$}} \\
\hline & & & & & & & & \\
\hline & & & & & & & & \\
\hline & $\begin{array}{c}\text { DM-1 } \\
\left(w_{j}\right)\end{array}$ & $\begin{array}{c}\text { DM-2 } \\
\left(w_{k}\right)\end{array}$ & $\begin{array}{l}\text { DM-1 } \\
(\alpha)\end{array}$ & $\begin{array}{c}\text { DM-2 } \\
(\beta)\end{array}$ & $\begin{array}{c}\text { DM-1 } \\
(\alpha)\end{array}$ & $\begin{array}{c}\text { DM-2 } \\
(\beta)\end{array}$ & $\begin{array}{c}\text { DM-1 } \\
(\alpha)\end{array}$ & $\begin{array}{c}\text { DM-2 } \\
(\beta)\end{array}$ \\
\hline$C_{11}$ & 0.44 & --- & \multirow{2}{*}{0.50} & --- & \multirow{2}{*}{0.55} & --- & \multirow{2}{*}{0.45} & --- \\
\hline$C_{12}$ & 0.56 & --- & & --- & & --- & & --- \\
\hline$C_{21}$ & --- & 0.19 & --- & \multirow{5}{*}{0.50} & --- & \multirow{5}{*}{0.45} & --- & \multirow{5}{*}{0.55} \\
\hline$C_{22}$ & --- & 0.21 & --- & & --- & & --- & \\
\hline$C_{23}$ & --- & 0.18 & --- & & --- & & --- & \\
\hline$C_{24}$ & --- & 0.20 & --- & & --- & & --- & \\
\hline$C_{25}$ & --- & 0.22 & --- & & --- & & --- & \\
\hline
\end{tabular}

\section{Results and discussion}

Three different cases representing different combinations for importance of theoretical and practical aspects when forming overall assessments are investigated: Case-1, Case-2 and Case-3. Case-1 considers the theoretical knowledge and practical skills with equal importance, while Case- 2 emphasises on the theoretical importance rather than practical skills. Case-3 expresses the opposite situation of Case-2 where the most important are practical skills rather than the theoretical knowledge. All of these cases share the same input data as shown in Table 2.

The obtained results about the overall assessment of the students by using the classical SMART and proposed e-SMART are visualized in Fig. 2.

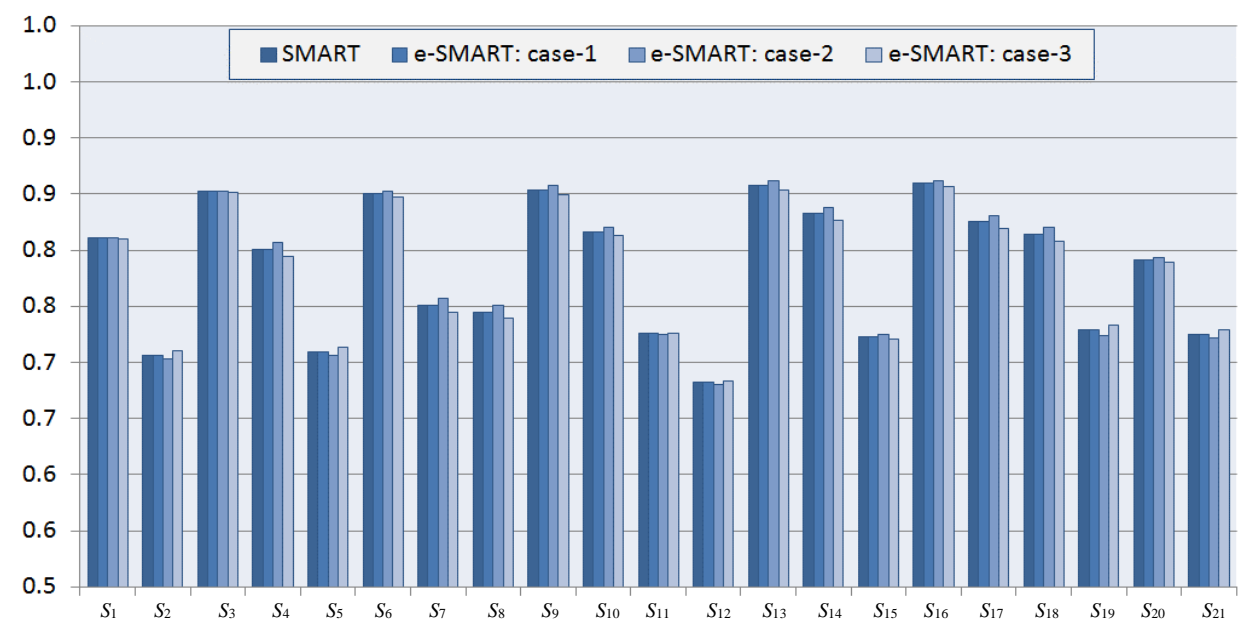

Fig. 2. Students' assessment by classical SMART and e-SMART

The obtained results (Fig. 2) for students' assessments by using of e-SMART in three different cases share the same weights for the criteria importance as it is shown in the first two columns in Table 3. These results are used to compare the students' 
ranking by using classical SMART and the proposed e-SMART in three different cases as shown in Table 4.

Table 4. Students ranking by classical SMART and e-SMART

\begin{tabular}{|c|c|c|c|c|}
\hline \multirow{2}{*}{ Students } & \multicolumn{5}{|c|}{ Ranking } \\
\cline { 2 - 5 } & Classic SMART & e-SMART (Case-1) & e-SMART (Case-2) & e-SMART (Case-3) \\
\hline$S_{1}$ & 10 & 10 & 10 & 9 \\
\hline$S_{2}$ & 20 & 20 & 20 & 20 \\
\hline$S_{3}$ & 4 & 4 & 4 & 11 \\
\hline$S_{4}$ & 11 & 11 & 11 & 19 \\
\hline$S_{5}$ & 19 & 19 & 19 & 5 \\
\hline$S_{6}$ & 5 & 5 & 5 & 13 \\
\hline$S_{7}$ & 13 & 13 & 13 & 14 \\
\hline$S_{8}$ & 14 & 14 & 14 & 8 \\
\hline$S_{9}$ & 3 & 3 & 3 & 17 \\
\hline$S_{10}$ & 8 & 8 & 8 & 21 \\
\hline$S_{11}$ & 16 & 16 & 16 & 6 \\
\hline$S_{12}$ & 21 & 21 & 21 & 18 \\
\hline$S_{13}$ & 2 & 2 & 1 & 1 \\
\hline$S_{14}$ & 6 & 6 & 6 & 7 \\
\hline$S_{15}$ & 18 & 18 & 17 & 10 \\
\hline$S_{16}$ & 1 & 1 & 2 & 15 \\
\hline$S_{17}$ & 7 & 7 & 7 & 12 \\
\hline$S_{18}$ & 9 & 9 & 9 & 16 \\
\hline$S_{19}$ & 15 & 15 & 17 & \\
\hline$S_{20}$ & 12 & 12 & 12 & 18 \\
\hline$S_{21}$ & 17 & 17 & & 6 \\
\hline & & & 18 & \\
\hline
\end{tabular}

The obtained students' rank list when using classical SMART and e-SMART in Case-1 show identical results. This is an expected result, because Case-1 of the e-SMART model simulates the situation with equal importance of the theoretical knowledge and practical skills.

When using the proposed e-SMART model in Case-2 the corresponding students' rank list differs from the classical SMART and e-SMART in Case-1 (see Table 4). There are five students with different positions within rank list when Case-2 is used and they are as follows: $S_{13}, S_{15}, S_{16}, S_{19}$ and $S_{21}$. For example, in Case1 the student $S_{16}$ is at the top in rank list followed by $S_{13}$ (same as the classical SMART), while in Case-2 where more weight is put on the theoretical knowledge, the student $S_{13}$ is the first in the rank list followed by $S_{16}$.

The obtained results in Case- 3 and using the proposed e-SMART model (more importance of practical skills than theoretical knowledge) show major differences in the ranked students. The following six students: $S_{1}, S_{3}, S_{9}, S_{11}, S_{18}$ and $S_{21}$ have differences in positions in the rank lists for Case-1 and Case-3. The comparison between the rank lists for Case-2 and Case-3 shows different positions for the following ten students: $S_{1}, S_{3}, S_{9}, S_{11}, S_{13}, S_{15}, S_{16}, S_{18}, S_{19}$ and $S_{21}$. The graphical visualization of students' ranking using classical SMART and the proposed e-SMART model under three different cases is shown in Fig. 3. 


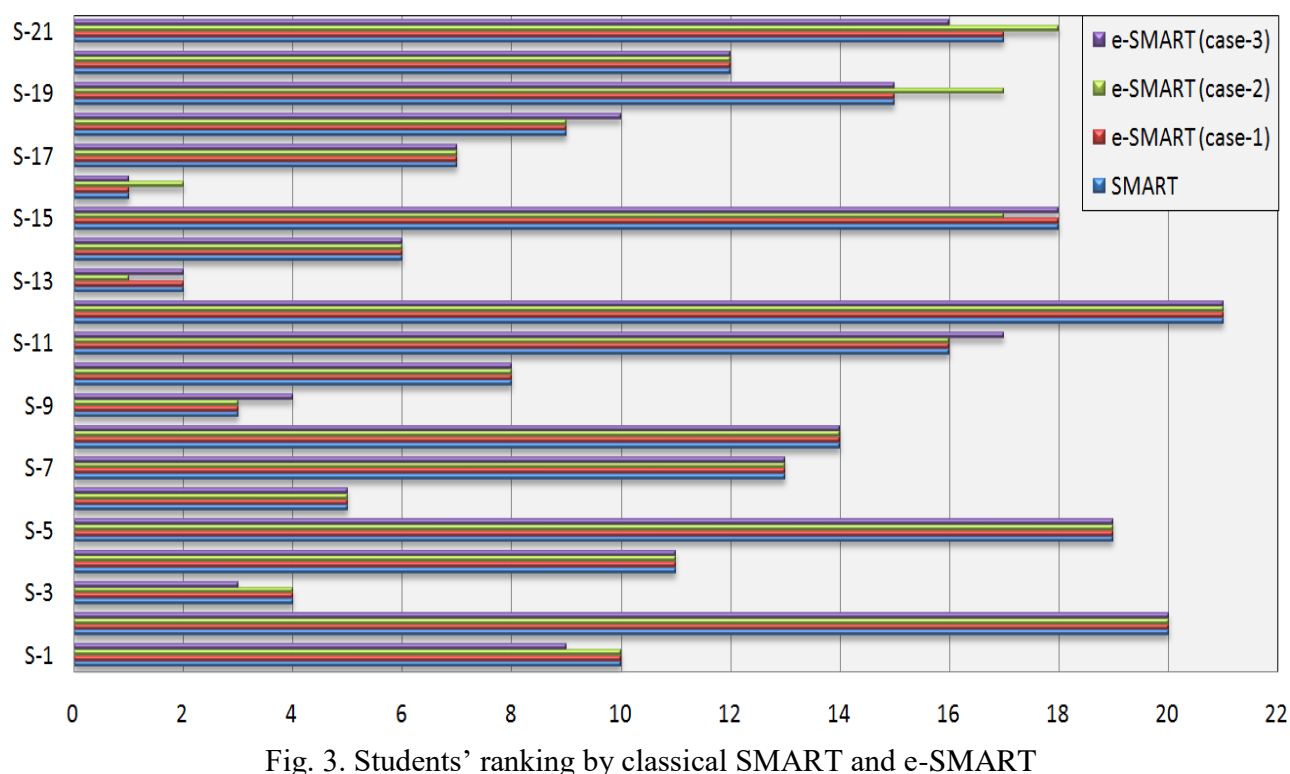

It should be noted that there is some limited number of students that preserve the position in the rank list despite of the used models and simulated situations regarding the importance of theoretical knowledge and practical skills. The students without change in the position in the ranking are as follows: $S_{2}, S_{4}, S_{5}, S_{6}, S_{7}, S_{8}, S_{10}$, $S_{12}, S_{14}, S_{17}$ and $S_{20}$ (see Table 4). These eleven students represent $52.38 \%$ of the entire group. For the rest of the students who are $47.62 \%$ it is highly important how theoretical knowledge and practical skills will be considered in the aggregated final assessment.

The advantage of the proposed utility function is the ability to take into account not only evaluations about the criteria and their corresponding weights for importance, but involving also additional weights for theoretical and practical outcomes that play an essential role in the ranking of students. The obtained ranking of the students could be used for different purposes. For example, such a ranking contributes to dividing the total number of students into small groups in the relevant specialty. In this case the different courses could be interpreted as evaluation criteria and the corresponding assessments by score will form the overall ranking. The relative weights about the courses could be assigned by the group authorized to perform the ranking lists.

The described case study is based on $5 \%$ differences in favour of theoretical knowledge in Case-2 and $5 \%$ differences in favour of practical skills in Case-3. Determination of the percentage of predominance will be subject to future developments. In contrast to [16] where the focal point is the prediction of student performance, the current paper aims to propose the ranking of the students considering their achievements in the theoretical and practical aspects. 


\section{Conclusion}

The paper describes a flexible approach for evaluation and ranking of students using multi-attribute decision making techniques. The proposed modified utility function takes into account with different importance theoretical and practical aspects of the learning. The main contribution is the usage of the introduced coefficients that indicate how theoretical knowledge and practical skills take part in the aggregated final assessment. The formulated e-SMART model is used for ranking of the students by evaluation in respect to two major criteria and several sub-criteria about the acquired theoretical knowledge and practical skills.

The applicability of the proposed approach is illustrated for the case of assessing and ranking of students from web programming course. The described case study concerns assessing and ranking of the students from bachelor programme "Information and Computer Sciences" at the University of Library Studies and Information Technologies for academic year 2018/2019. It is shown that using the proposed e-SMART approach determines different students' rank lists having different importance about the theoretical knowledge and practical skills. Similar rank lists of students could contribute in determination of students oriented to scientific research or practical implementation.

The described modelling approach based on new utility function is able to summarise together the evaluation scores, weights for criteria importance, and weights about the theoretical and practical aspects. There are no restrictions about the number of the basic criteria and their sub-criteria and respectively for the number of DMs to be involved in the process of students' assessment. In this regard, the future investigation of the discussed problem is related to the aspects of e-testing and its assessment and integration for the purpose of students' ranking.

\section{References}

1. Gutierrez, R. T. Understanding the Role of Digital Commons in the Web; The Making of HTML5. - Telematics and Informatics, Vol. 35, 2018, pp. 1438-1449.

2. R i n g e, S., R. K e d i a, A. P o d d a r, S. P a t e l. HTML5 Based Virtual Whiteboard for Real Time Interaction. - Procedia Computer Science, Vol. 49, 2015, pp. 170-177.

3. Halachev, P., I. Mustakerov. Evaluation of the Time Needed for e-Learning Course Developing. - Cybernetics and Information Technologies, Vol. 9, 2009, No 3, pp. 86-95.

4. Mustake rov, I., D. B or is s o va. A Framework for Development of e-Learning System for Computer Programming: Application in the C Programming Language. - Journal of e-Learning and Knowledge Society, Vol. 13, 2017, No 2, pp. 89-101.

5. Mustakerov, I., D. B or is sova. A Conceptual Approach for Development of Educational Web-Based e-Testing System. - Expert Systems with Applications, Vol. 38, 2011, No 11, pp. 14060-14064.

6. Tu parov, G., D. Keremedchiev, D. Tuparova, M. S to y a nova. Gamification and Educational Computer Games in Open Source Learning Management Systems as a Part of Assessment. - In: Proc. of 17th Int. Conf. Information Technology Based Higher Education and Training (ITHET'18), Olhao, 2018, pp. 1-5. doi: 10.1109/ITHET.2018.8424768.

7. Borissova, D., I. Mustakerov. e-Learning Tool for Visualization of Shortest Paths Algorithms. - Trends Journal of Sciences Research, Vol. 2, 2015, No 3, pp. 84-89. 
8. Mardan i, A., A. J u s o h, K. MD N or, Z. Kh a li fa h, N. Z a kw a n, A. V a 1 i p o u r. Multiple Criteria Decision-Making Techniques and Their Applications - A Review of the Literature from 2000 to 2014. - Economic Research-Ekonomska Istraživanja, Vol. 28, 2015, No 1, pp. 516-571.

9. Le e, L., R. A n d e r s o n. A Comparison of Compensatory and Non-Compensatory Decision Making Strategies in IT Project Portfolio Management. - International Research Workshop on IT Project Management 2009. 9. 2009.

http://aisel.aisnet.org/irwitpm2009/9

10. Ke eney, R. L., H. Raiffa. Decisions with Multiple Objectives: Preferences and Value Tradeoffs. - Cambridge University Press, 1993. 592 p.

11. B a r z i l a i, J. Preference Function Modelling: The Mathematical Foundations of Decision Theory, in Trends in Multiple Criteria Decision Analysis. Springer. - International Series in Operations Research \& Management Science, Vol. 142, 2010, pp. 57-86.

12. P e n e v a, V., I. P o p c h e v. Fuzzy Multi-Criteria Decision Making Algorithms. - Compt. Rend. Acad. bulg. Sci., Vol. 63, 2010, No 7, pp. 979-992.

13. P e n e va, V., I. P o p che v. Multicriteria Decision Making by Fuzzy Relations and Weighting Functions for the Criteria. - Cybernetics and Information Technologies, Vol. 9, 2009, No 4, pp. 58-71.

14. La Red Martinez, D. L., J. C. Acosta. Review of Modeling Preferences for Decision Models. - European Scientific Journal, Vol. 11, 2015, No 36, pp. 1-18.

15. I 1 i e v a, G. Group Decision Analysis Algorithms with EDAS for Interval Fuzzy Sets. - Cybernetics and Information Technologies, Vol. 18, 2018, No 2, pp. 51-64.

16. Kabakchieva, D. Predicting Student Performance by Using Data Mining Methods for Classification. - Cybernetics and Information Technologies, Vol. 13, 2013, No 1, pp. 61-72.

17. Radeva, I. Multi-Criteria Models for Clusters Design. - Cybernetics and Information Technologies, Vol. 13, 2013, No 1, pp. 18-33.

18. Tz e n g, G-H., J-J. H u a n g. Multiple Attribute Decision Making: Methods and Applications. CRC Press, 2011. 352 p.

19. Triant a ph y 11 o u, E. Multi-Criteria Decision Making Methods. In: Multi-Criteria Decision Making Methods: A Comparative Study. - Applied Optimization, Vol. 44, 2000, Springer, Boston, MA, $320 \mathrm{p}$. https://doi.org/10.1007/978-1-4757-3157-6_2

20. O 1 s o n, D. L. Smart. - In: Decision Aids for Selection Problems. Springer Series in Operations Research, 1996, pp 34-48.

21. Opricovic, S., G.-H. Tzeng. Compromise Solution by MCDM Methods: A Comparative Analysis of VIKOR and TOPSIS. - European Journal of Operational Research, Vol. 156, 2004, No 2, pp. 445-455.

22. Sirisawat, P., T. Ki at charoenpol. Fuzzy AHP-TOPSIS Approaches to Prioritizing Solutions for Reverse Logistics Barriers. - Computers \& Industrial Engineering, Vol. 117, 2018, pp. 303-318.

23. A b d e 1-B a s e t, M., V. C h a n g, A. G a m a l, F. S m a r a n d a c h e. An Integrated Neutrosophic ANP and VIKOR Method for Achieving Sustainable Supplier Selection: A Case Study in Importing Field. - Computers in Industry, Vol. 106, 2019, pp. 94-110.

24. Korse mov, D., D. B oris s ova, I. Mustakerov. Combinatorial Optimization Model for Group Decision-Making. - Cybernetics and Information Technologies, Vol. 18, 2018, No 2, pp. 65-73.

25. Stancheva, N., A. Stoyanova-Doycheva, S. Stoyanov, I. Popchev, V. I vanova. An Environment for Automatic Test Generation. - Cybernetics and Information Technologies, Vol. 17, 2017, No 2, pp. 183-196.

26. Stancheva, N., A. Stoy anova-Doycheva, S. Stoyanov, I. Popchev, V. I v a n o v a. A Model for Generation of Test Questions. - Compt. Rend. Acad. bulg. Sci., Vol. 70, 2017, No 5, pp. 619-630.

Received: 07.05.2019; Second Version: 12.07.2019; Accepted: 24.07.2019 